\title{
Preliminary Design of Heliostat Field and Performance Analysis of Solar Tower Plants with Thermal Storage and Hybridisation
}

\author{
Srilakshmi Gopalakrishnan ${ }^{\text {a }}$ S Suresh N S ; $^{\text {b Thirumalai N C }}$; M A Ramaswamy ${ }^{\text {d }}$
}

${ }^{a}$ Corresponding Author: Research Engineer,

Phone: +91 (80) 66902594, E-mail: srilakshmi@ cstep.in

${ }^{\mathrm{b}} \mathrm{Sr}$. Research Engineer,

Phone: +91(80) 66902536, E-mail: suresh@ cstep.in

${ }^{\mathrm{c}}$ Research Scientist,

Phone: +91(80)66902505, E-mail: thirumalai@cstep.in

${ }^{\mathrm{d}}$ Advisor,

Phone: +91(80) 66902554, E-mail: mar@ cstep.in

Address: Center for Study of Science, Technology and Policy (CSTEP), $10^{\text {th }}$ Cross, Papanna Layout, Mayura Street, Outer Ring Road, Bangalore, Karnataka, India -560 094

\begin{abstract}
Solar tower technology has gained considerable momentum over the past decade. In a solar tower plant, a single receiver is used and the power collected by the heliostat field is strongly coupled to the tower height and its location with respect to the field. The literature available focuses largely on the component-level details of the heliostat field, ray-tracing mechanisms, receiver heat transfer analyses, etc. However, there is no systematic method to determine the preliminary optimum tower height and solar field together with an estimation of a solar tower plant's technical performance. The present paper provides a methodology to estimate the design performance of a tower plant (with storage and hybridisation) using an external cylindrical receiver. The methodology is validated with the Gemasolar plant in Spain and the Crescent Dunes plant in the United States of America. The optimum efficiency is $16 \%$ for the Gemasolar plant (20 MW and 15 hours of storage) and $18.3 \%$ for the Crescent Dunes plant (110 MW and 10 hours of storage). Further, the methodology is applied to hypothetical plants in Jodhpur as a case study and the results are analysed. The trends seen are similar to that observed for parabolic trough plants.
\end{abstract}

Keywords: Solar Tower; Thermal Storage; Hybridization; Tower Height; Concentrated Solar Power 


\section{Nomenclature}

\begin{tabular}{|c|c|c|}
\hline Symbol & Variable Name & Units \\
\hline$D N I_{i}$ & $\begin{array}{l}\text { Hourly Direct Normal Irradiance at the location } \\
\text { for the } i^{\text {th }} \text { hour }\end{array}$ & $\mathrm{W} / \mathrm{m}^{2}$ \\
\hline$L A$ & Total land area & $\mathrm{m}^{2}$ \\
\hline$M A$ & Total mirror area & $\mathrm{m}^{2}$ \\
\hline$N_{f}$ & Number of points under boundary chosen by user & \\
\hline$P D$ & Packing density at point $p$ of the field & \\
\hline$P_{c a p, d}$ & Design plant capacity & MW \\
\hline$P_{h t f, i}$ & $\begin{array}{l}\text { Thermal power input to the heat exchanger from } \\
\text { solar field for the } i^{\text {th }} \text { hour }\end{array}$ & W \\
\hline$P_{i}$ & Solar power impinging on receiver for hour $i$ & $\mathrm{~W}$ \\
\hline$P_{\text {imax }}$ & Maximum of the $P_{i}$ values (over 8760 hours) & $\mathrm{W}$ \\
\hline$P_{S, d}$ & Design solar power required from the field & $\mathrm{W}$ \\
\hline$S M$ & Solar Multiple & \\
\hline$S_{n, j}$ & $\begin{array}{l}\text { Slant distance from point } j \text { of the solar field to } \\
\text { the receiver (this is effectively } S_{n, n d, j} \times h \text { ) }\end{array}$ & $\mathrm{km}$ \\
\hline$\frac{d_{x}}{h}$ and $\frac{d_{y}}{h}$ & Non-dimensional length/width of elemental area & \\
\hline$e_{g}$ & $\begin{array}{l}\text { Gross electrical energy that would be generated } \\
\text { during the hour without considering energy } \\
\text { needed for start-up }\end{array}$ & Wh \\
\hline$e_{g a}$ & $\begin{array}{l}\text { Gross hourly electrical energy available after } \\
\text { accounting for start-up }\end{array}$ & Wh \\
\hline$e_{g a, t}$ & Total annual gross electrical energy available & Wh \\
\hline$e_{\text {grid }, t}$ & $\begin{array}{l}\text { Total annual gross electrical energy supplied to } \\
\text { the grid }\end{array}$ & Wh \\
\hline$e_{h b, t}$ & $\begin{array}{l}\text { Total annual gross electrical energy apportioned } \\
\text { to hybridisation }\end{array}$ & Wh \\
\hline$e_{l}$ & $\begin{array}{l}\text { Annual reflected energy per unit land area of the } \\
\text { solar field (taking into account cosine effect and } \\
\text { packing density) }\end{array}$ & $\mathrm{Wh} / \mathrm{m}^{2}$ \\
\hline$e_{s, t}$ & $\begin{array}{l}\text { Total annual gross electrical energy apportioned } \\
\text { to solar input }\end{array}$ & Wh \\
\hline
\end{tabular}




\begin{tabular}{|c|c|c|}
\hline$f_{h b}$ & Fraction of hybridisation power & \\
\hline$f_{p}$ & $\begin{array}{l}\text { Fraction of the design gross electrical power } \\
\text { generated ignoring thermal losses during } \\
\text { shutdown }\end{array}$ & \\
\hline$f_{p a}$ & $\begin{array}{l}\text { Ratio of electrical power generated to the rated } \\
\text { capacity }\end{array}$ & \\
\hline$f_{t h}$ & $\begin{array}{l}\text { Fraction of design thermal power delivered to } \\
\text { power block }\end{array}$ & \\
\hline$h$ & Height of the tower & $\mathrm{m}$ \\
\hline$h[1]_{i}$ & Initial height of tower at $S M=1$ & \\
\hline$h[1]$ & Final height of tower at $S M=1$ & $\mathrm{~m}$ \\
\hline$h[S M]$ & Height of tower for a given $S M$ & $\mathrm{~m}$ \\
\hline$h_{\text {new }}[1]$ & Height variable used during iteration & $\mathrm{m}$ \\
\hline$i$ & Number of hours (varies from 1 to 8760 ) & \\
\hline$j$ & $\begin{array}{l}\text { Set of all points under boundary (varies from } 1 \text { to } \\
N_{f} \text { ) }\end{array}$ & \\
\hline$p$ & Each point in the field & \\
\hline$r$ & $\begin{array}{l}\text { Radial distance from the base of the tower to a } \\
\text { point in the field }\end{array}$ & $\mathrm{m}$ \\
\hline$r / h$ & $\begin{array}{l}\text { Non-dimensionalised radial distance of point } \\
(x / h, y / h) \text { from the tower }\end{array}$ & \\
\hline$\left(\frac{r}{h}\right)_{\min }$ & $\begin{array}{l}\text { Minimum non-dimensional distance of the solar } \\
\text { field from the tower }\end{array}$ & \\
\hline$t_{s}$ & Number of hours of thermal storage & Hours \\
\hline$x / h$ & $\begin{array}{l}\text { Non-dimensionalised } x \text { coordinate of a point in } \\
\text { the field }\end{array}$ & \\
\hline$y / h$ & $\begin{array}{l}\text { Non-dimensionalised } y \text { coordinate of a point in } \\
\text { the field }\end{array}$ & \\
\hline$\Delta h$ & Height increment & $\mathrm{m}$ \\
\hline$\eta_{a t t, j}$ & Attenuation efficiency of point $j$ & fraction \\
\hline$\eta_{h e}$ & Heat exchanger efficiency & fraction \\
\hline$\eta_{m}$ & Mirror efficiency & fraction \\
\hline$\eta_{p b}$ & Power block efficiency & fraction \\
\hline$\eta_{\text {receiver }}$ & Receiver efficiency & fraction \\
\hline$\eta_{s-e}$ & Annual solar-to-electric conversion efficiency & in $\%$ \\
\hline
\end{tabular}



point $p$ 


\section{Introduction}

A Solar Tower (ST) makes use of a large number of heliostats or mirrors (which have a dual-axis control system to track the sun's rays throughout the day) to reflect the solar energy impinging on them onto a receiver that is located at the top of a tower. Concentrated solar energy that falls on the receiver is transferred to a Heat Transfer Fluid (HTF), which passes through the receiver. The thermal energy of the HTF is then transferred to a working fluid in the power block, by means of a heat exchanger, thereby generating electricity. ST systems generally have a storage component that allows for a part of the solar energy that is collected to be stored for later use. A schematic illustration of an ST plant is shown in Fig. 1.

The available literature on ST covers component-level analyses, specifically on heliostats and their tracking mechanisms [1-4], shadowing and blocking effect algorithms [5], receiver performance and heat transfer analyses [6-7], and heliostat layout optimisation studies [8-9]. Reviews of the many components in this technology as well as existing plants that are in operation and under construction have also been performed [10-11]. Empirical guidance on the preliminary sizing and specification of a heliostat field is provided in [12]. However, the present literature lacks an overall methodology to model a complete ST plant from scratch (with given inputs such as hourly Direct Normal Irradiation $(D N I)$ data at the plant location, capacity, thermal storage hours, gross efficiencies, etc.) as was done for the Parabolic Trough (PT) technology [13].

In recent times, the use of ST technology has increased considerably and it is comparable to PT technology. Traditional PV arrays and wind turbine are subjected enormously to the vagaries of nature and are not easily available for large capacity energy storage. Consequently, they are not suitable for large scale dispatchable power. On the other hand, ST technology with thermal storage and hybridisation offers an alternative means of using renewable energy for large scale dispatchabale power.

The primary objective of this study is to develop a methodology to carry out a technical analysis of a ST, similar to the one carried out for a PT plant in CSTEP's Solar Techno-Economic Model (CSTEM). The working of the PT tool model is described in detail in [13-14]. While attempting to do this, it was realised that due to fundamental differences between the PT and ST technologies, a straightforward extension of the methodology could not be used for an ST. On studying these differences, it was observed that the crux of the issue is that in the case of PT, the solar energy that can be collected by the receiver is directly proportional to the land area of the solar field. However, in the case of an ST, the solar energy that can be collected by the solar field is a complex function of the solar field layout relative to the tower. Therefore, the first pre-requisite for developing a methodology analogous to that developed for PT [13], was to obtain a rational method for fixing the boundary of the solar field around the tower in terms of the variation of the non-dimensional quantity, $r / h$, with respect to the azimuth angle, where $r$ is the radial distance from the tower and $h$ is the height of the tower. This method is explained in detail in [15] but an outline is discussed in Section 2. Once the coupling between tower height and the heliostat solar field is established, it has been possible to extend the methodology used for PT, with some modifications, to an ST to determine the optimum tower height and the corresponding solar field for a given capacity of steam Rankine power cycle with specified hours of storage and limited hybridisation.

This paper describes the methodology to determine the optimum solar field, associated tower height and plant performance of an ST that uses an external cylindrical receiver and molten salt as both the HTF and storage medium, operating with a steam Rankine power cycle, by utilising this coupling between tower height and solar field through a non-dimensional solar field.

The inputs to the model and the details of the methodology are explained in Section 3. Section 4 describes the validation of the model. Section 5 describes a case study on a hypothetical ST plants 
located at Jodhpur (India), for various capacities, with different hybridisation and thermal storage capacities, followed by the concluding remarks in Section 6 .

\section{Determination of Non-Dimensional Solar Field Boundary}

A rational method for fixing this non-dimensional boundary is explained in detail in [15]. This method is applicable to a solar field with radially staggered heliostats and using an external cylindrical receiver. An outline of this method is briefly covered in this section.

This non-dimensional boundary depends on the following:

1) Location of the plant (latitude)

2) Hourly DNI data for the plant

3) Variation of the Packing Density $(P D)$ of heliostats (ratio of local heliostat area and land area) with $r / h$.

Considering the variation of the $P D$ of a few existing ST plants, a nominal variation of $P D$ with $r / h$ as given in Eq. (1), Eq. (2) and Eq. (3) has been assumed for this analysis.

$$
\begin{aligned}
& P D=0 \quad \text { for } \frac{r}{h}<\left(\frac{r}{h}\right)_{\min } \\
& P D=0.492-0.0939 \frac{r}{h} \quad \text { for }\left(\frac{r}{h}\right)_{\min } \leq \frac{r}{h} \leq 2.8 \\
& P D=\frac{0.6}{\sqrt{\left(\frac{r}{h}\right)^{2}-1}} \text { for } \frac{r}{h}>2.8 .
\end{aligned}
$$

The variation of $P D$ with $r / h$ is shown in Fig. 2 .

The steps involved in the method for fixing the non-dimensional solar field boundary are as follows:

1) A non-dimensional solar field of extent $-10 \leq x / h \leq+10$ and $-10 \leq y / h \leq+10$ is considered ( $Y$ axis being along the north-south direction) and field points in this region, spaced $d_{x} / h$ and $d_{y} / h$ from the $X$ and $Y$ coordinate axes, are chosen.

2) Knowing the non-dimensionalised coordinates $(x / h$ and $y / h)$ of any field point $p, r / h$ can be determined by Eq. (4).

$$
\frac{r}{h}=\sqrt{\left(\frac{x}{h}\right)^{2}+\left(\frac{y}{h}\right)^{2}}
$$

The corresponding $P D$ of point $p$ can be determined.

3) For a given location (latitude), for any given hour $i$ of the 8760 hours of a year, the declination, hour, zenith, altitude and azimuth angles can be calculated. Then $\theta_{i, p}$, the angle between the incident ray and the normal to the heliostat located at field point $p$, can be calculated [16]. This allows us to determine the cosine effect $\left(\cos \theta_{i, p}\right)$.

4) The annual solar energy per unit land area, $e_{l}$ (taking into account the $P D$ ), in $\mathrm{MWh} / \mathrm{m}^{2}$ that can be collected from point $p$ of the solar field and reflected onto the receiver is computed using Eq. (5).

$$
e_{l}=(P D) \sum_{i=0}^{8760} D N I_{i} \times \cos \theta_{i, p} / 10^{6},
$$

where $D N I_{i}$ is the $D N I$ in $\mathrm{W} / \mathrm{m}^{2}$ for the hour $i$. 
5) Since all existing plants are generally symmetric w.r.t. the north-south direction, the $e_{l}$ values are made symmetric at each $y / h$ by using Eq. (6).

$$
e_{l(x / h)}=e_{l(-x / h)}=\frac{e_{l(x / h)}+e_{l(-x / h)}}{2} .
$$

6) A particular value for $e_{l}$ equal to $e_{l c h o s e n}$ is chosen for fixing the outer solar field boundary. This value is chosen based on the fact that if the energy collected per unit area of the solar field is lesser than a particular value, then it is economically undesirable to use it as a solar field. This value has to be determined from many practical economic considerations, but taking a cue from existing plants (Gemasolar, PS10 and PS20, and Crescent Dunes) the default value chosen is $0.16 \mathrm{MWh}$ annually per unit solar field area.

7) For ST plants, the solar field starts beyond a certain minimum value of $r / h$, given as $(r /$ $h)_{\text {min }}$. All points ranging from $j=1$ to $N_{f}$, which have $e_{l}$ values greater than or equal to $e_{l c h o s e n}$ and $r / h$ values greater than $(r / h)_{\min }$, are identified as solar field points for the plant. It may be noted that these non-dimensional field points for an ST depend only on the hourly $D N I$ data at the location of the plant and the variation of $P D$ with $r / h$, and are independent of the plant capacity $\left(P_{c a p, d}\right)$ or the number of hours of thermal storage $\left(t_{s}\right)$.

8) For all solar field points $j=1$ to $N_{f}, \cos \theta_{i, p}$ corresponding to each hour $i$ for all 8760 hours in the year is stored and these are utilised in the methodology for determining the physical field boundary for a given $P_{c a p, d}, t_{s}$ and fraction of hybridisation $\left(f_{h b}\right)$, and the corresponding technical performance of the ST plant. Details are provided in the next section.

\section{Methodology for Determination of Tower Height and Technical Assessment of ST Plants}

The methodology is similar to that, which was followed for PT plants [13]. However, the adaptation of the methodology for an ST is different from that for PT as is highlighted in this section.

\subsection{Overview of the Methodology}

In the present paper, the scope of the methodology is limited to the use of molten salt both as heat transfer fluid and thermal storage medium. Further, a steam Rankine cycle is considered for the power block. The inputs needed for applying this methodology are given below.

i. Location of the ST plant (latitude)

ii. Hourly DNI data

iii. Minimum $r / h$ and $e_{l}$ values for the boundary

iv. Design plant capacity (MW)

v. Full load plant efficiency as a function of plant capacity

vi. Effect of part load on efficiency

vii. Empirical model to consider thermal losses during plant shutdown

viii. Efficiencies of various systems: Receiver, mirror and heat exchanger

ix. Number of hours of thermal storage

x. Extent of hybridisation for augmentation as a fraction of design thermal power

The outline of the methodology is presented in the flowchart provided in Fig. 3. 


\subsection{Determination of tower height for SM=1 and the Reference Solar Field Area}

The inputs are the location of the plant; DNI data for a Typical Meteorological Year (TMY); latitude $(\phi)$; plant capacity $\left(P_{c a p, d}\right)$; and the efficiencies of the mirrors $\left(\eta_{m}\right)$, receiver $\left(\eta_{\text {receiver }}\right)$ and heat exchanger $\left(\eta_{h e}\right)$. Apart from these, non-dimensional lengths $d_{x} / h$ and $d_{y} / h$, and coordinate points $x / h$ and $y / h$ for all points $N_{f}$ falling in the non-dimensional solar field (as discussed in Section 2) are also used. For considering attenuation, one of two models can be considered: Clear or Hazy day, depending on atmospheric visibility conditions.

In the present paper, we limit the scope to a steam Rankine cycle to run the power block. The power block efficiency $\left(\eta_{p b}\right)$ depends on many factors, for example, the inlet pressure and temperature of steam, condenser pressure, capacity of turbine and mass flow rate of steam. The variation of gross maximum power block efficiency with turbine inlet temperature for different turbine outlet temperatures is given in [14]. Based on the variation of gross maximum efficiency with turbine inlet temperature, the final power block efficiency conditions (which have been used in this model) are given in Eq. (7) and Eq. (8). The turbine inlet and outlet temperatures have been taken as $\sim 560^{\circ} \mathrm{C}$ and $70^{\circ} \mathrm{C}$, respectively.

$$
\begin{array}{llrl}
\eta_{p b}=0.441-0.262 \times e^{-0.06 \times P_{\text {cap }, d}} & & \text { for } 0 \leq P_{\text {cap }, d}<50 \\
\eta_{p b}=0.44 & \text { for } \quad P_{\text {cap }, d} \geq 50 .
\end{array}
$$

Using these inputs, the reference solar field area is determined using the following procedure:

1) The design solar power, $P_{s, d}$, that needs to impinge on the central receiver to generate the electric power corresponding to $P_{c a p, d}$, taking into account $\eta_{p b}, \eta_{h e}$ and $\eta_{\text {receiver }}$, is computed as given in Eq. (9).

$$
P_{s, d}=\frac{P_{\text {cap }, d} \times 10^{6}}{\eta_{\text {receiver }} \times \eta_{h e} \times \eta_{p b}} .
$$

2) The minimum physical solar field area, corresponding to $S M=1$, which is needed to provide the power $P_{s, d}$ to the receiver (at the peak DNI $\times \cos \theta$ out of 8760 hours of the year) needs to be determined. In the case of PT, $P_{s, d}$ is directly proportional to the solar field area, and, hence, it is straightforward to determine the physical solar field corresponding to $S M=1$. But for an ST, $P_{s, d}$ is dependent on both the solar field and its relation to the tower location and height. Since the solar field is now coupled to the tower through the non-dimensional field described in the previous section, the determination of the solar field corresponding to $S M=1$ is equivalent to the determination of tower height at $S M=1$.

It may also be noted that $P_{i}$ (in $\mathrm{W}$ ), the solar power impinging on the receiver for hour $i$, is dependent on the tower height in a complex manner as given in Eq. (10).

$P_{i}=\left(\left(\frac{d_{x}}{h} \times \frac{d_{y}}{h}\right) \times \eta_{m} \times \sum_{j=1}^{N_{f}} D N I_{i} \times \cos \theta_{i, j} \times P D \times \eta_{a t t, j}\right) \times(h)^{2}$,

where $\eta_{a t t, j}$ is the attenuation efficiency at point $j$. It depends on whether a clear-day model [Eq. (11)] or a hazy-day model [Eq. (12)] is used [16].

$$
\eta_{a t t, j}=0.99326-0.1046 S_{n, j}+0.017 S_{n, j}^{2}-0.002845 S_{n, j}^{3}
$$

or 
$\eta_{a t t, j}=0.98707-0.2748 S_{n, j}+0.03394 S_{n, j}{ }^{2}$,

where $S_{n, j}$ is the slant height of point $j$ from the receiver at the top of the tower in kilometres and is given by Eq. (13).

$S_{n, j}=\left(\sqrt{(x)^{2}+(y)^{2}+(h)^{2}}\right) / 1000$.

As can be seen, $\eta_{a t t, j}$ is a function of the height of the tower. The task is to find the value of $h$ such that the maximum of all $8760 P_{i}$ values, $P_{\text {imax }}$, is equal to $P_{s, d}$.

Since it is an implicit equation, $h$ is determined by iteration.

First, the initial value of $h$ at $S M=1, h[1]_{i}$, is determined by taking $\eta_{a t t, j}=1$ (zeroattenuation condition). Then, $h[1]_{i}$ is calculated using Eq. (14).

$h[1]_{i}=\sqrt{\frac{P_{S, d}}{\left(\frac{d_{x}}{h} \times \frac{d_{y}}{h}\right) \times \eta_{m} \sum_{j=1}^{N_{f}} D N I_{i} \times \cos \theta_{i, j} \times P D \times 1}}$.

If $P_{\text {imax }}$ is calculated with this value of $h$, considering attenuation, it will naturally be lesser than $P_{S, d}$.

Therefore, a numerical iterative procedure is used for determining $h_{\text {new }}[1]$ by incrementing $h$ in steps of $\Delta h$ such that for a particular value of $h_{\text {new }}[1], P_{\text {imax }}$ is lesser than or equal to $P_{s, d}$ and for $\left(h_{\text {new }}[1]+\Delta h\right), P_{\text {imax }}$ is greater than $P_{s, d}$.

The value of $\Delta h$ is initially taken to be $5 \mathrm{~m}$ and subsequently reduced in steps of $0.1 \mathrm{~m}$, such that, $h_{\text {new }}[1]$ is determined to an accuracy of $0.1 \mathrm{~m}$. This converged value of $h$ is taken as the final height $h[1]$ of the tower corresponding to $S M=1$.

3) With the solar field corresponding to $S M=1$, the power generated will be less than $P_{c a p, d}$ at all hours other than the peak hour. Therefore, the solar field design involves choosing an optimum solar field with $S M$ greater than 1, after taking into account the storage and hybridisation constraints. The consideration for determining the optimum $S M$ can be based on the coincide state of $\eta_{s-e}$ vs. SM and Levelised Cost of Electricity (LCOE) vs. SM, if cost inputs are available. In the present study, optimisation is based on maximum $\eta_{s-e}$.

\subsection{Solar Power Input to the Heat Exchanger at a Chosen SM}

The height corresponding to $S M=1$ once found is then used to determine the height at higher $S M$ s, using Eq. (15).

$$
h[S M]=h[1] \times \sqrt{S M} .
$$

This relation is chosen since the physical solar field area is roughly proportional to $h^{2}$.

It may be noted that $h[1]$ is based only on the capacity of the plant. Other parameters like hours of thermal storage and extent of hybridisation do not play any part in this calculation. Once $h[S M]$ is calculated, the actual power input to the heat exchanger is computed for each hour of the year, using Eq. (16).

$$
P_{h t f, i}=\left(\left(\frac{d_{x}}{h} \times \frac{d_{y}}{h}\right) \eta_{m} \times \eta_{\text {receiver }} \sum_{j=1}^{N_{f}} D N I_{i} \times \cos \theta_{i, j} \times P D \times \eta_{a t t, j}\right) \times(h[S M])^{2},
$$

where $\eta_{a t t, j}$ is a function of $h[S M]$. 


\subsection{Annual Electrical Energy Generated}

The annual electrical energy generated by the plant taking into account the thermal storage and hybridisation constraints is computed. The optimum $S M$ that gives the highest $\eta_{s-e}$ is chosen for fixing the optimum tower height and the corresponding solar field. Except for the fact that the solar power generated is proportional to the $S M$ in the case of PT, the methodology to account for thermal storage and hybridisation, and for arriving at the optimum $S M$, is identical to that employed for PT. For every hour, the fraction of thermal power delivered to the power block $\left(f_{t h}\right)$, the fraction of gross electrical power generated ignoring thermal losses during shutdown $\left(f_{p}\right)$ and the ratio of electrical power generated to the rated capacity $\left(f_{p a}\right)$ are computed. The electrical energy generated without accounting for start-up losses $\left(e_{g}\right)$, the electrical energy generated after accounting for start-up losses $\left(e_{g a}\right)$, the total annual electrical energy generated after accounting for start-up losses $\left(e_{g a, t}\right)$ and the annual electricity to the grid $\left(e_{\text {grid, }, t}\right)$ are computed. The total electrical energy apportioned to hybridisation $\left(e_{h b, t}\right)$ and that apportioned to solar $\left(e_{s, t}\right)$, the Capacity Utilisation Factor (CUF) and $\eta_{s-e}$ are all computed using the methodology identical to that in [13].

The total Mirror Area (MA) and the total Land Area ( $L A)$ are computed using Eq. (17) and Eq. (18), respectively.

$$
\begin{aligned}
& M A=\left(\sum_{j=1}^{N_{f}} P D\right) \times\left(\frac{d_{x}}{h} \times \frac{d_{y}}{h}\right) \times(h[S M])^{2} \\
& L A=\left\{\left(N_{f} \times\left[\frac{d_{x}}{h} \times \frac{d_{y}}{h}\right]\right)+\left(\pi \times\left(\left(\frac{r}{h}\right)_{\text {field min }}\right)^{2}\right)\right\} \times(h[S M])^{2} .
\end{aligned}
$$

The solar energy input is considered as (Annual $D N I \times M A$ ). Thereby, the value of $\eta_{s-e}$ is defined as the ratio of the annual electrical energy generated to the solar energy input.

\subsection{Determination of the Preliminary Design of Tower Height, Solar Field and Performance of ST}

For the specified capacity, storage hours and extent of hybridisation, the variation of $\eta_{s-e}$ with SM is considered. The SM, for which $\eta_{s-e}$ is maximum, is used for the preliminary design of tower height and solar field. Subsequently, the performance of the plant is estimated. In this paper, the economic aspects are not considered. However, if information regarding cost and other financial aspects is known, one can go further and determine the variation of LCOE with SM and choose the SM that corresponds to the least LCOE, for the design. Once SM is known, the height, physical solar field and technical performance of the designed ST can be easily estimated.

\section{Validation of Model}

Based on the methodology discussed, a Java-based Graphical User Interface (GUI) tool called CSTEM - CSTEP's Solar Techno-Economic Model - has been developed. This tool helps to perform hourly simulation of Concentrated Solar Power (CSP) plants using the PT as well as ST technology for various capacities taking into account thermal storage and hybridisation as well.

The default values of various parameters used in this model are shown in Table 1.

To confirm the validity of this model, ST Plant data of Gemasolar (20 MW with 15 hours of storage and 0.15 factor of hybridisation) and Crescent Dunes (110 MW with 10 hours of storage) 
were taken and this model was applied to see how the preliminary design obtained by this model compared with the actual values of the plant regarding tower height, land and mirror area, as well as the annual electrical energy generated. The comparison is shown in Table 2. Considering there are many parameters, like the efficiencies of various components, the $P D$ variation assumed and the $e_{l}$ boundary chosen, whose values used in the model may be different from those of the plant, it can be concluded that as a first-order approximation, the results obtained from the model are quite satisfactory.

It is found that the optimum $S M$ occurs at $S M=2.75$ for Gemasolar $\left(\eta_{s-e}=16 \%\right)$ and $S M=2.5$ for Crescent Dunes $\left(\eta_{s-e}=18.3 \%\right)$.

Apart from the efficiencies of various components, the parameters that are important for the model are the $P D$ variation assumed and the $e_{l}$ boundary value. In fact, these are coupled. The $P D$ variation assumed lies roughly along the mean of the data available up to $r / h=6.0$. Beyond that, extrapolation is done to obtain the $P D$ for higher $r / h$ values. The solar field of Crescent Dunes extends beyond an $r / h$ of 6 , up to about 8 . Therefore, if our extrapolated values are different from those used by them, error is likely to be more.

It may also be pointed out that the actual $P D$ variation used in the plants is not smooth and there are kinks when extra heliostats are added to the ring whenever permitted by the circumferential distance. Therefore, if the heliostat pattern for a plant is finalised, the exact $P D$ variation and boundary can be fixed for the chosen $e_{l}$ value. The important thing to note is that with proper inputs, the model is capable of generating a reasonable first-cut preliminary design for the ST plant, which can be refined in the more detailed design.

\section{Application of the Model to Jodhpur as a Case Study: Results and Discussion}

In this section, the results of applying the engineering model developed for hypothetical ST plant located in Jodhpur are discussed. Jodhpur $\left(\phi=26.26^{\circ}\right)$ is chosen because it is one of the locations in India that receive high annual $D N I$. The $D N I$ data for this analysis are taken from CSTEP report [17]. The parameters chosen for the study are shown in Table 3.

For various combinations of these parameters, $\eta_{s-e}$, CUF and the annual electricity generated have been computed for various $S M$ values between one and four in suitable steps.

The results are presented and discussed below.

\subsection{Case 1: No Thermal Storage and No Hybridisation}

This section analyses the effect of various plant parameters when no thermal storage or hybridisation is used. The variation of the CUF with $S M$ for all capacities is shown in Fig. 4. It can be seen that the CUF tends to saturate beyond $S M=4$. With increased SM, the excess power generated beyond the capacity of the plant cannot be utilised and the heliostats have to be defocussed. Hence, the CUF gets saturated with increased SM.

The variation of $\eta_{s-e}$ with $S M$ for various capacities is plotted in Fig. 5. From this figure, it can be seen that the maximum efficiency occurs at an $S M$ value of about 1.4 for all capacities and the efficiency increases with capacity, reaching a value of about $18 \%$ for a $50-\mathrm{MW}$ plant.

\subsection{Case 2: Thermal Storage without Hybridisation}

In this section, thermal storage for 3, 6 and 15 hours of storage has been considered for plants of capacities 1, 5, 10, 20, 35 and $50 \mathrm{MW}$. The effect of $S M$ and storage hours on $\eta_{s-e}$ has been discussed. 


\subsubsection{Effect of $S M$}

The variation of annual energy generated per MW with $S M$, for thermal storage of 0,6 and 15 hours (for various capacities) and with no hybridisation, is shown in Fig. 6. Since the variation in annual energy generated is proportional to the capacity, in this case, the variation of the CUF with $S M$ is similar to the case when no storage hours are used. From Fig. 6, one can also see that as the number of hours of thermal storage increases, the $S M$ should also increase (otherwise the system is not efficient). The requirement of higher thermal storage hours implies the need for a higher SM.

The variation of $\eta_{s-e}$ with $S M$ for various capacities for 6 hours of thermal storage is shown in Fig. 7. It is observed that in this case, the highest efficiency occurs at $S M=2.1$ and it is independent of plant capacity. It can also be seen that the overall efficiency increases as the capacity of the plant increases. This is mainly due to higher efficiencies offered by the power block at higher plant capacities.

\subsubsection{Variation of Optimum SM with Storage Hours $\left(f_{h b}=0\right)$}

The $S M$ corresponding to the maximum $\eta_{s-e}$ is considered as the optimum SM (which is independent of plant capacity). Fig. 8 shows the variation of the optimum $S M$ with number of hours of storage (with no hybridisation). A linear trend is observed with number of hours of thermal storage. As mentioned earlier, this optimum SM is independent of the capacity of the plant.

\subsection{Case 3: Hybridisation without Thermal Storage}

In this section, the effect of hybridisation (without thermal storage) on different parameters of the plant is discussed. Hybridization is mainly used to augment the thermal power from the heliostat field. In the present case, this is restricted to the extent of 0.2 times the rated thermal power.

\subsubsection{Effect of Hybridisation on the hourly variation of fractional thermal power and fractional electrical power}

In this section, the hourly variation of fractional solar power, $f_{t h, s}\left(P_{h t f} / P_{h t f, d}\right)$, and fractional electrical power, $f_{p a}$ (electrical power generated/rated capacity), for a typical day (January 21) for $S M=1$ and $S M=1.5$ is shown.

Note that $f_{p a}=e_{g a} /\left(P_{c a p, d} \times 10^{6}\right)$ and $f_{p}=e_{g} /\left(P_{c a p, d} \times 10^{6}\right)$. The advantage of representing $f_{t h, s}$ and $f_{p a}$ is that they are independent of the capacity of the plant.

Fig. 9 shows the variation of $f_{p a}$ over a typical day for $f_{h b}=0,0.1$ and 0.2 along with $f_{t h, s}$ for $S M=1$. Note that for the day chosen, $f_{t h, s}$ is of the order of 1.0 even during mid-day.

With no hybridisation $\left(f_{h b}=0\right)$, there is a lag in power generation, since $f_{t h, s}$ is initially used up for compensating thermal losses over-night. Beyond 9 hours, $f_{p a}$ nearly follows $f_{t h, s}$.

For $f_{h b}=0.1$, there is a lag for $f_{p a}$ relative to $f_{t h, s}$ but it is lesser. $f_{p a}$ is higher than $f_{t h, s}$ beyond 8 hours. However, the upper limit of $f_{p a}=1.1$ has not been reached even during mid-day.

For $f_{h b}=0.2$, the lag gets further reduced. Between 10 to 14 hours, $f_{p a}$ reaches a limit of 1.1 and the available $f_{h b}$ is only partly used.

These aspects are made clear in Fig. 10 where $f_{h b}$ utilised during the day is shown. It can be seen when $f_{h b}=0.1$, it is utilised throughout whereas when $f_{h b}=0.2$, it is utilised only partly between 10 to 14 hours. 
Fig. 11 shows the variation of $f_{p a}$ over a typical day for $f_{h b}=0,0.1$ and 0.2 along with $f_{t h, s}$ for $S M=1.5$. With $\mathrm{SM}=1.5, f_{t h, s}$ itself is beyond 1.1 between 9 to 16 hours. Therefore, there is no need for augmentation from hybridisation during these hours. The amount of hybridisation utilised during the day is shown in Fig.12. It may be seen that between 7 to 8 hours and 16 to 17 hours, the extent of hybridisation of 0.1 or 0.2 is utilised. Between 8 to 9 hours, $f_{h b}$ of approximately 0.02 only is utilised.

From the above, it is obvious, as the SM increases, solar power $f_{t h, s}$ increases. Even at $\mathrm{SM}=1.5$, for the day considered, augmentation needed through hybridisation is very small. Therefore, $\mathrm{SM}>1.5$ has not been used for the analysis.

Fig. 12 gives the value of $f_{h b \text {,used }}$ during the day. It can be seen that the amount of energy from the field $\left(f_{t h, s}\right)$ is sufficient to run the plant at 1.1 times the full capacity for most of the day, and, hence, there is no necessity of hybridisation for most of this period. It can be observed that for the first hour, $f_{t h, s}$ and hybridisation contribute towards compensating for the thermal losses that have occurred overnight. So the amount of energy generated for this hour, $f_{p a}$, is small. This can be contrasted with the last hour where $f_{p a}$ is not as less as it is for the first hour.

Since at SM values greater than 1.5 , the solar field itself might be sufficient to cater the needs of the power block, higher SMs have not been considered in this analysis.

\subsubsection{Effect of Hybridisation on the Annual Efficiency Attributed to the Solar Field}

Fig. 13 shows the variation of $\eta_{s-e}$ with $S M$ for $f_{h b}=0,0.1$ and 0.2 for capacities of $1 \mathrm{MW}$ and $50 \mathrm{MW}$ (with no thermal storage). It can be seen that the higher the hybridisation factor, the higher is the overall efficiency. However, the benefit of hybridisation decreases as the $S M$ increases.

\subsection{Case 4: Thermal Storage and Hybridisation}

CUF is independent of the rated capacity of the plant. Fig. 14 and Fig. 15 show the variation of the CUF with $S M$ for 0 and 6 hours of storage, respectively. In both these figures, hybridisation values of $0,0.1$ and 0.2 are considered. It can be seen that the CUF increases with $S M$, but the benefit of hybridisation is maximum for $S M=1$ and decreases as $S M$ increases as shown in the previous section. It may also be noted that benefit of thermal storage is felt for higher SMs beyond 1.5 .

\subsection{Height of Tower at Optimum $S M\left(f_{h b}=0\right)$}

From section 2, it is seen that the optimum SM depends only on the number of hours of thermal storage $\left(t_{s}\right)$ and not on the capacity of the plant. However, the optimum physical height of the tower and the corresponding physical solar field for the optimum SM is a function of the capacity of the plant. Fig. 16 shows the variation of tower height with capacity for thermal storage of 0,6 and 15 hours (and no hybridisation) at the respective optimum SMs. This case was taken just to give an idea of the variation of tower height with capacity at optimum SM.

\subsection{Comparison of Results for Clear- vs. Hazy-Day Attenuation Models}

Attenuation, as explained earlier, depends on the actual slant distance from a heliostat to the top of the receiver. At any instant, the attenuation is an integrated effect of all the heliostats in field.. The effect of attenuation on the performance of $1 \mathrm{MW}$ and $50 \mathrm{MW}$ ST plant with 6 hours of storage and no hybridisation (optimum $S M=2.1$ ) is shown in Table 4.

This case has been taken as an example to illustrate the degree by which the annual electrical energy generated and $\eta_{s-e}$ reduce when the hazy-day model ( $<23 \mathrm{~km}$ visibility) is used. It can be 
seen that the reduction is quite substantial when the capacity is higher: the annual electrical energy reduces by $3.3 \%$, while $\eta_{s-e}$ reduces by about $10.4 \%$ (for a $50-\mathrm{MW}$ plant). This is expected because for larger capacities, the field is bigger and, consequently, the slant distances are larger. The effect of the haziness of the atmosphere is negligible for plants with smaller capacities.

Therefore, in actual practice, for analysing higher-capacity plants, the hourly variation of atmospheric effects needs to be taken into consideration.

\section{Conclusion}

A rational method has been developed for the preliminary design of a solar tower plant with a given capacity, thermal storage and hybridisation similar to the one that had been developed for a parabolic trough plant [13]. It was possible to develop such a methodology by utilising the method for defining a non-dimensional solar field boundary in terms of tower height [15]. The methodology has been validated by comparing the results obtained by this method with those used in the Gemasolar and Crescent Dunes plants with regard to tower height and solar field area.

Based on this study, a Java-based tool - CSTEM for Solar Tower - has been developed. This tool was used to generate data on hypothetical plants in Jodhpur, of various capacities, thermal storage hours and hybridisation. It was found that the optimum SMs for plants using 0, 6 and 15 hours of storage are 1.4, 2.1 and 3.2, respectively. These are found to be independent of the capacity of the plant. Since cost data are still not comprehensively available for this technology, the annual solarto-electrical efficiency $\left(\eta_{s-e}\right)$ was taken as the criterion for choosing the optimum SM. It is found that the annual efficiency increases with increase in the capacity of the plant. It is observed that hybridisation is more effective at lower SMs. Hybridisation also improves the plant efficiency by allowing the power block to operate at better part load conditions. For a plant of $20 \mathrm{MW}$ and with 6 hours of storage, the optimum height of the tower is found to be about $105 \mathrm{~m}$. It is found that atmospheric attenuation does not play a significant role when the capacities are low.

In the case of a cavity receiver, the field is also intimately coupled with the design of the cavity receiver (the angle subtended by the opening of the receiver, etc.). The angle subtended by the field is a function of the type of cavity and is not very amenable for generalisation. If the cavity angle is known, the present study can be extended to cavity receivers as well.

It is recommended, that just as in the case of the CSTEM tool for Parabolic Trough, the CSTEM tool for Solar Tower can be used to analyse plant performance. The tool can be used by designers, developers and policymakers to facilitate an initiatory design to estimate the optimum height of the tower and, thereby, the size and performance of the solar field for a plant of a given capacity (using thermal storage and hybridisation).

\section{Acknowledgement}

This paper is based on the work done at CSTEP supported in part under the US-India Partnership to Advance Clean Energy-Research (PACE-R) for the Solar Energy Research Institute for India and the United States (SERIIUS), funded jointly by the U.S. Department of Energy (Office of Science, Office of Basic Energy Sciences, and Energy Efficiency and Renewable Energy, Solar Energy Technology Program, under Subcontract DE-AC36-08GO28308 to the National Renewable Energy Laboratory, Golden, Colorado) and the Government of India, through the Department of Science and Technology under Subcontract IUSSTF/JCERDC-SERIIUS/2012 dated $22^{\text {nd }}$ November, 2012. The authors are grateful to Dr Anshu Bharadwaj, Executive Director, CSTEP for his constant support and guidance. The authors would also like to thank Dr. Mridula Dixit Bharadwaj, Principal Research Scientist, CSTEP for her encouragement and Dr. V S Chandrasekaran, Advisor, CSTEP for his critical review in improving the manuscript. 


\section{References}

[1] Belhomme, B., Pitz-Paal, R., Schwarzbözl, P., Ulmer, S., 2009. A new fast ray tracing tool for high precision simulation of heliostat fields. J. Sol. Energ-T ASME 131, 031002-1-8.

[2] Kiera, M., and Schiel, W., 1989. Measurement and analysis of heliostat images. J. Sol. EnergT ASME 111, 2-9.

[3] Wei Xiudong, Lu Zhenwu, Yu Weixing, Wang Zhifeng, 2010a. A new code for the design and analysis of the heliostat field layout for power tower system. J. Sol. Energy 84, 685-690.

[4] Wei Xiudong, Lu Zhenwu, Wang Zhifeng, Yu Weixing, Zhang Hongxing, Yao Zhihao, 2010b. A new method for the design of the heliostat field layout for solar tower power plant. J. Renew Energ 35, 1970-1975.

[5] Huang Weidong, Li Longlong, Li Yongping, Han Zhengfu, 2013. Development and evaluation of several models for precise and fast calculations of shading and blocking in heliostat field. J. Sol. Energy 95, 255-264.

[6] Fernández, P., and Miller, F.J., 2015. Performance analysis and preliminary design optimization of a small particle heat exchange receiver for solar tower power plants. J. Sol. Energy 112, 458-468.

[7] Kim Jongkyu, Kim Jin-Soo, Stein Wesley, 2015. Simplified heat loss model for central tower solar receiver. J. Sol. Energy 116, 314-322.

[8] Noone J Corey, Manuel Torrilhon, Mitsos Alexander, 2012. Heliostat field optimization: a new computationally efficient model and layout. J. Sol. Energy 86, 792-803.

[9] Pitz-Paal, R., Botero Bayer Nicolas, Steinfeld Aldo, 2011. Heliostat field layout optimization for high-temperature solar thermochemical processing. J. Sol. Energy 85, 334-343.

[10] Romero Manuel, Buck Reiner, Pacheco E James, 2002. An update on solar central receiver systems, projects and technologies. J. Sol. Energ-T ASME 124, 98-108.

[11] Srilakshmi Gopalakrishnan, Venkatesh, V., Thirumalai, N.C., Suresh, N.S., 2015. Challenges and Opportunities for Solar Tower Technology in India. J. Renew. Sust. Energ Rev. 45, 698-709.

[12] Vant-Hull, L.L., and Izygon, M.E., 2003. Guideline to central receiver system heliostat field optimization. Adv. Sol. Energy 15, 1-42.

[13] Suresh, N.S., Thirumalai, N.C., Rao S Badri, Ramaswamy, M.A., 2014. Methodology for sizing the solar field for parabolic trough technology with thermal storage and hybridization. J. Sol. Energy 110, 247-259.

[14] Ramaswamy, M.A., Chandrasekaran, V., Krishnan, R., Thirumalai, N.C., Suresh, N.S., Rao S Badri, Dolly K Smita, Kanth Chaitanya, Arun Kumar, V., 2012. Engineering Economic Policy Assessment of Concentrating Solar Technologies for India. Center for Study of Science Technology and Policy (CSTEP), Bengaluru.

[15] Gopalakrishnan Srilakshmi, N S Suresh, N C Thirumalai, M A Ramaswamy., 2016. A Novel Approach to Determine the Non-Dimensional Heliostat Field Boundary for Solar Tower Plants. J. Sustainable Energy Technologies and Assessments. 17, 26-37.

[16] Stine William and Geyer Michael. Power from the Sun, 2001. Chapter 10: Central Receiver Systems. URL: http://www.powerfromthesun.net/. Last Accessed 10 June 2016. 
[17] Ramaswamy, M.A., Rao S Badri, Thirumalai, N.C., Suresh, N.S., 2013. Estimation of Hourly Direct Normal Irradiance. Center for Study of Science Technology and Policy (CSTEP), Bengaluru. 


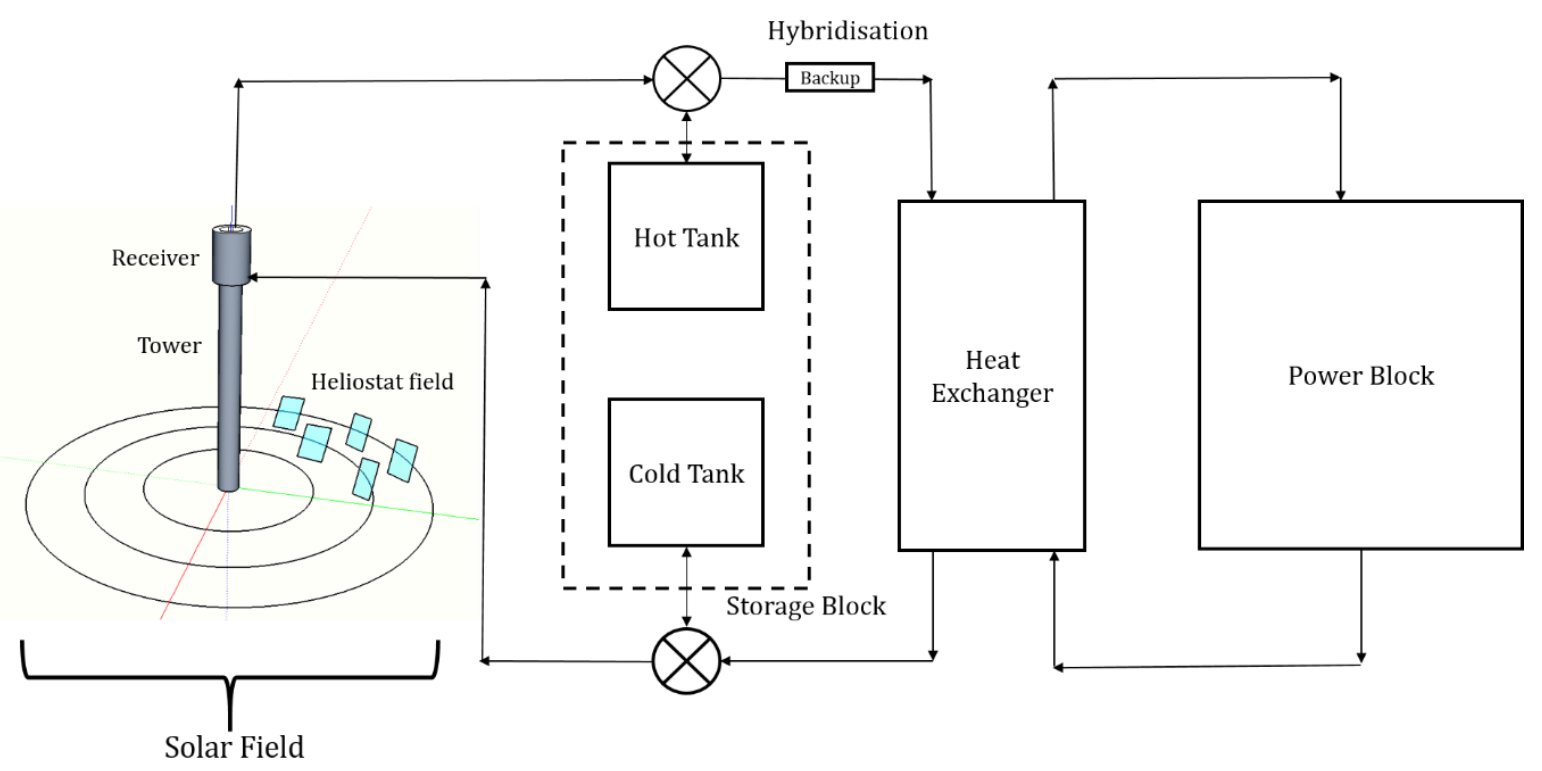

Fig. 1. Schematic of an ST Plant

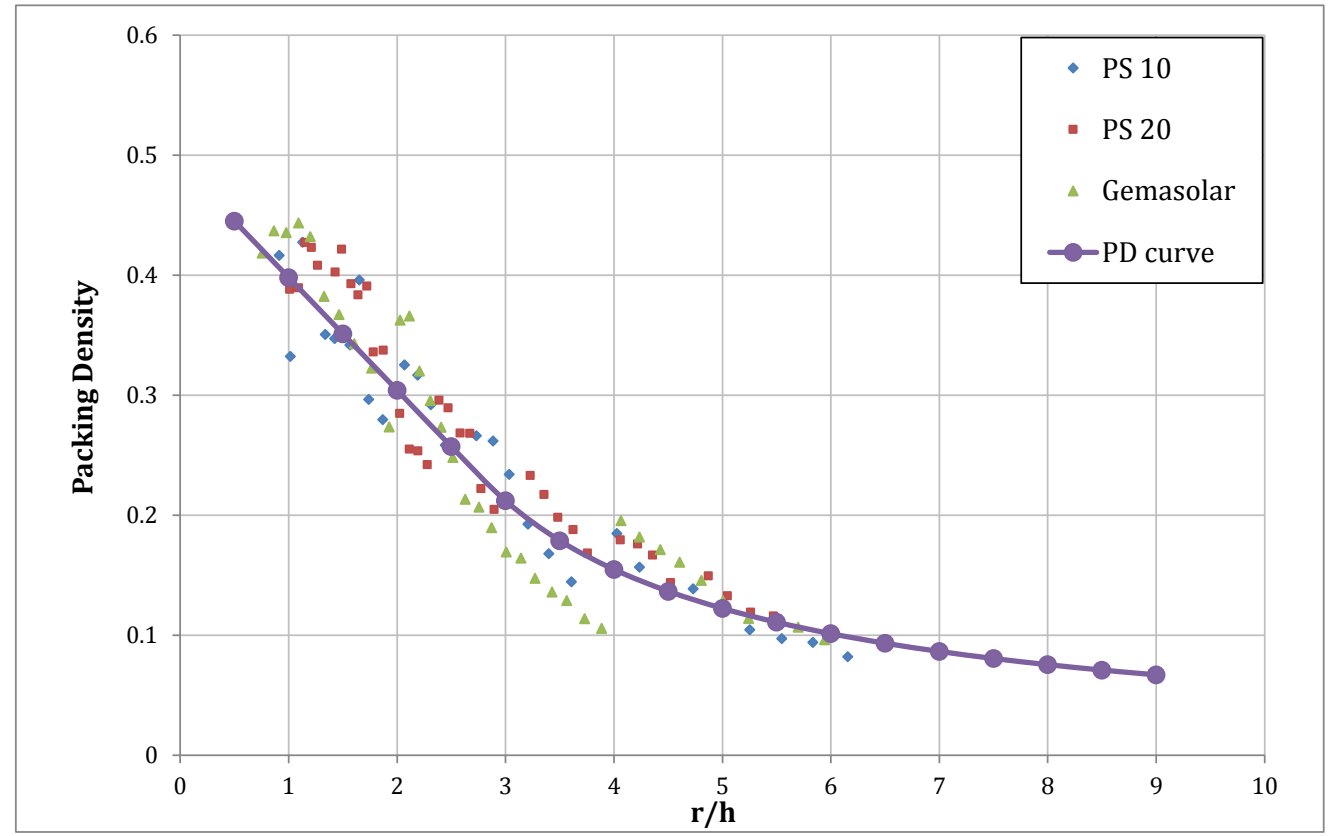

Fig. 2. Curve Fit Chosen to Account for $P D$ 
Firstly, determine the non-dimensional solar field boundary briefly explained in Section 2 above and described in detailed in [15]. This non-dimensional boundary depends only on latitude, hourly $D N I$ data and does not depend on the capacity of the plant.

(i) Determine the solar power $P_{s . d}$ that is needed to be collected from the solar field to generate the design electrical power by taking into account all system efficiencies.

(ii) The initial approximate tower height $h[1]_{i}$ needed to collect the design solar power $P_{s, d}$ is determined by neglecting the attenuation effects (i.e., taking $\eta_{a t t}=1.0$ ).

(iii) Then the correct height $h[1]$, considering the attenuation effects is determined through a converging iteration process. This $h[1]$ corresponds to tower height for $S M=1$. Since the nondimensional boundary is known, the reference solar field can be calculated.

Details of the above are explained in Section 3.2.

(i) $S M$ values ranging from 1.0 to 6.0 are chosen in suitable steps.

(ii) For the chosen $S M, h[S M]$ is taken as $h[1] \sqrt{S M}$ (since the solar field area is proportional to $h^{2}$ ).

(iii) Calculate for each of the 8760 hours, the thermal power input to HTF, $P_{h t f, i}$ taking into account $\eta_{m}, \eta_{\text {receiver }}, D N I$, cosine effect and attenuation for each of the heliostats.

(iv) Calculate the fractional solar thermal power $f_{t h, s}=P_{h t f, i} / P_{h t f, d}$, where $P_{h t f, d}$ is the design thermal power needed to generate electrical power.

Details of the above are explained in Section 3.3

(i) Once the solar thermal power has been transferred to the HTF, the rest of the system involved in converting this to electrical power utilizing thermal storage and hybridisation for ST are very similar to that for PT. Therefore, the complex logic which was used in the methodology for PT [13] for computing the electrical power for that hour, for the given value of $f_{t h, s}$ has been adopted.

(ii) Summing the electrical power generated over 8760 hours gives the annual electrical energy for chosen SM. The corresponding tower height and solar field and mirror area are calculated.

(iii) Annual solar energy input is calculated as mirror area multiplied by annual DNI.

(iv) The solar to electric efficiency $\left(\eta_{s-e}\right)$ is calculated as total annual electrical energy generated divided by the annual solar energy input.

All these aspects are covered in detailed in the methodology that has been applied for PT [13]. Hence, details are not repeated but briefly covered in Section 3.4

The optimum $S M$ is chosen as the one which gives the maximum $\eta_{s-e}$. The corresponding height and solar field can be taken as the preliminary design for the ST plant.

These aspects are covered in Section 3.5

Fig. 3: Flowchart Outlining the Methodology to Determine the Preliminary Design for ST plant 


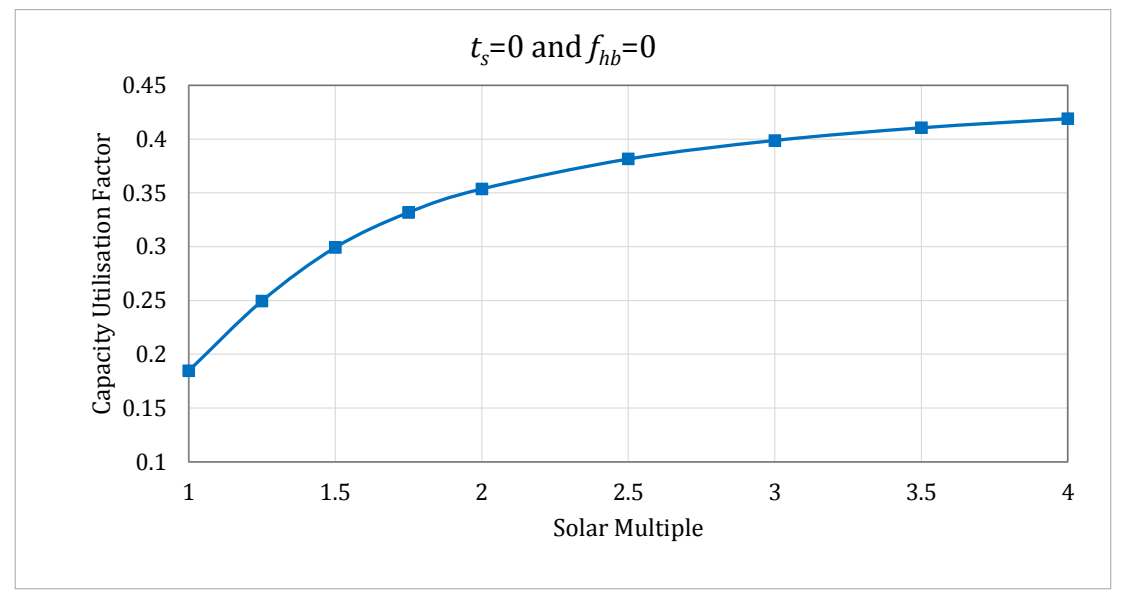

Fig. 4. Variation of CUF with $S M$ for all Capacities $\left(t_{s}=0\right.$ and $\left.f_{h b}=0\right)$

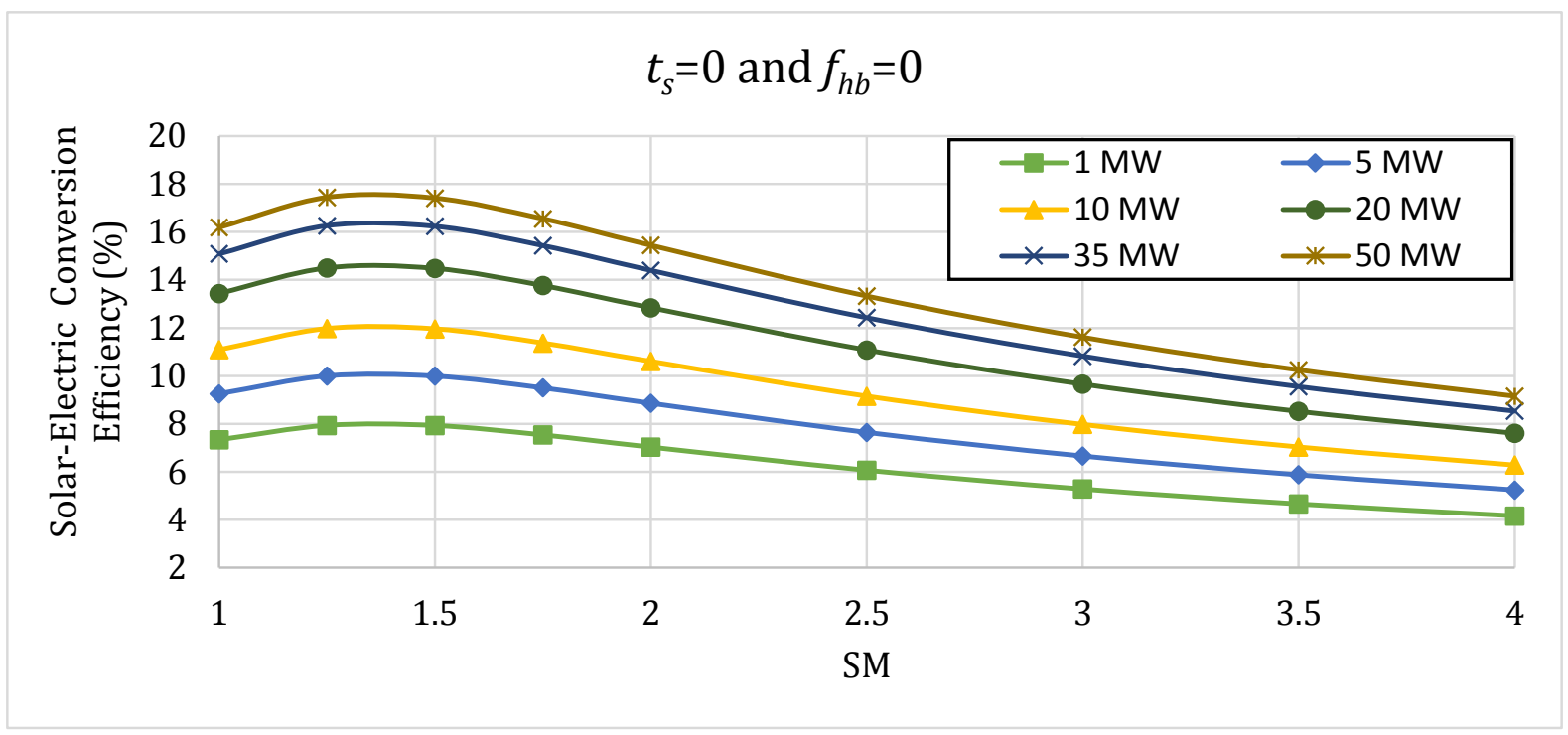

Fig. 5. Variation of $\eta_{s-e}$ with $S M$ for Various Capacities $\left(t_{s}=0\right.$ and $\left.f_{h b}=0\right)$

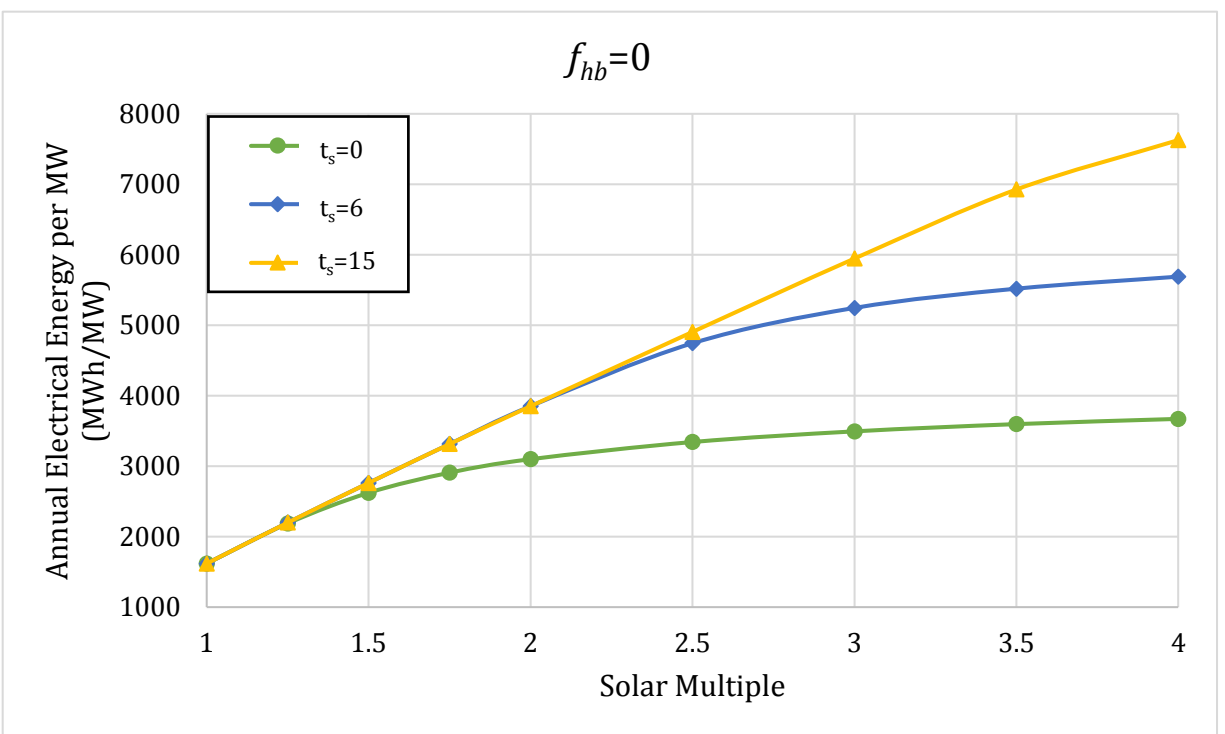

Fig. 6. Variation of Annual Electrical Energy/MW with $S M$ for $t_{s}=0,6$ and 15 hours $\left(f_{h b}=0\right)$ 


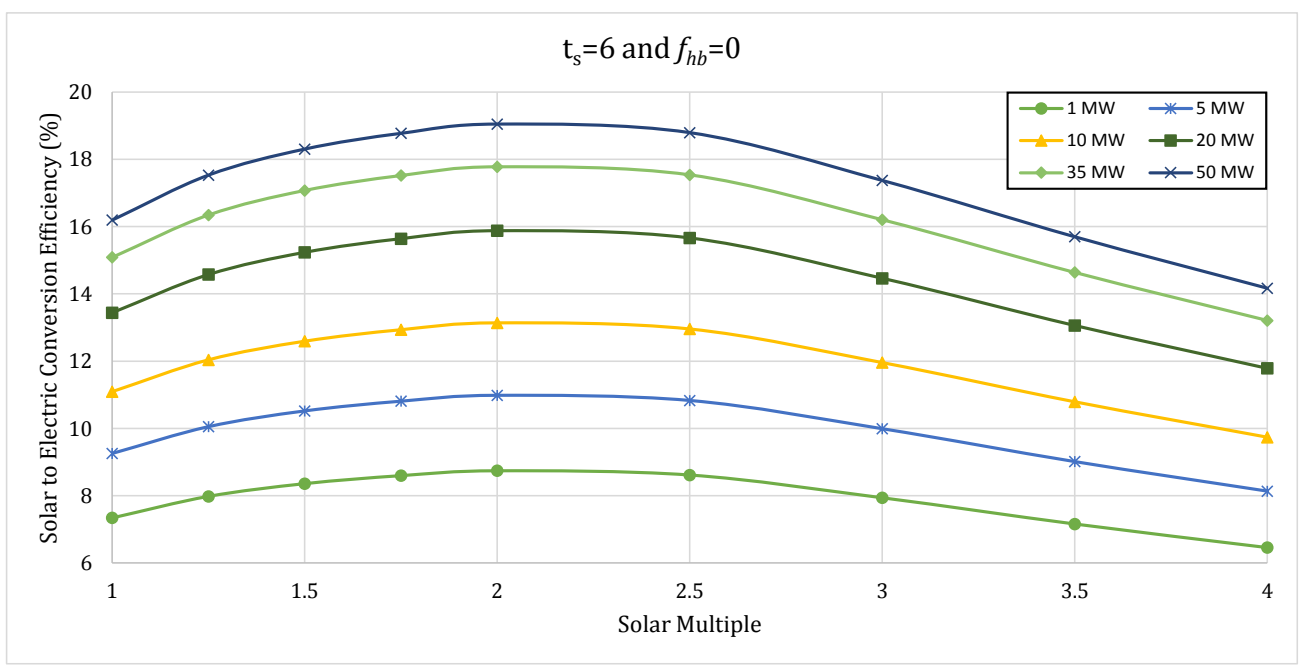

Fig. 7. Variation of Solar-to-Electric Conversion Efficiency with $S M$ for Various Capacities and $t_{s}=6$ hours $\left(f_{h b}=0\right)$

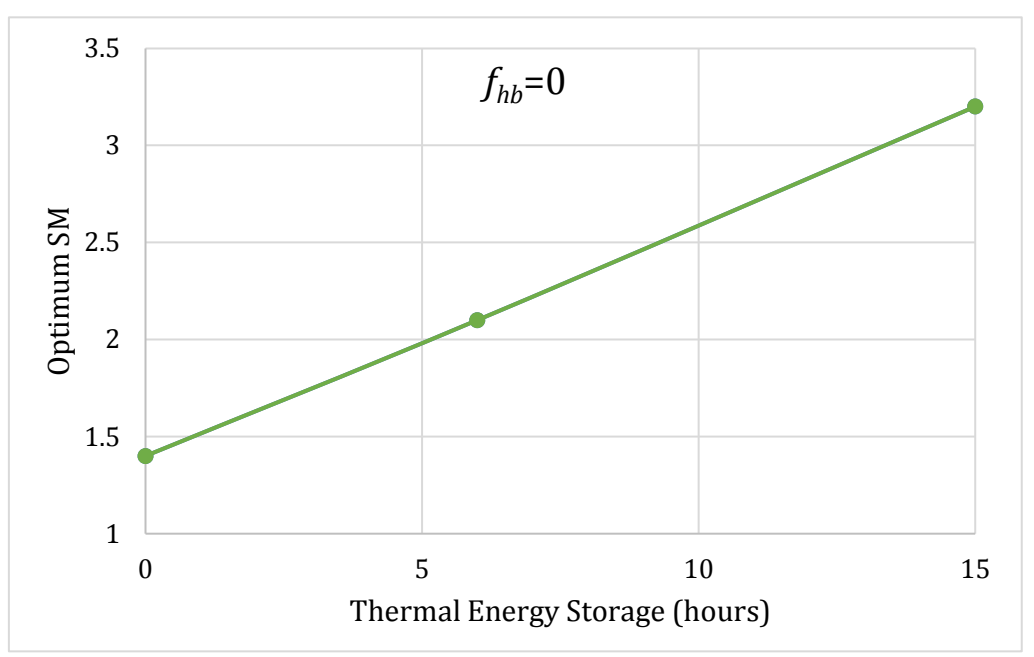

Fig. 8. Variation of Optimum $S M$ with Thermal Storage Hours $\left(f_{h b}=0\right)$ 


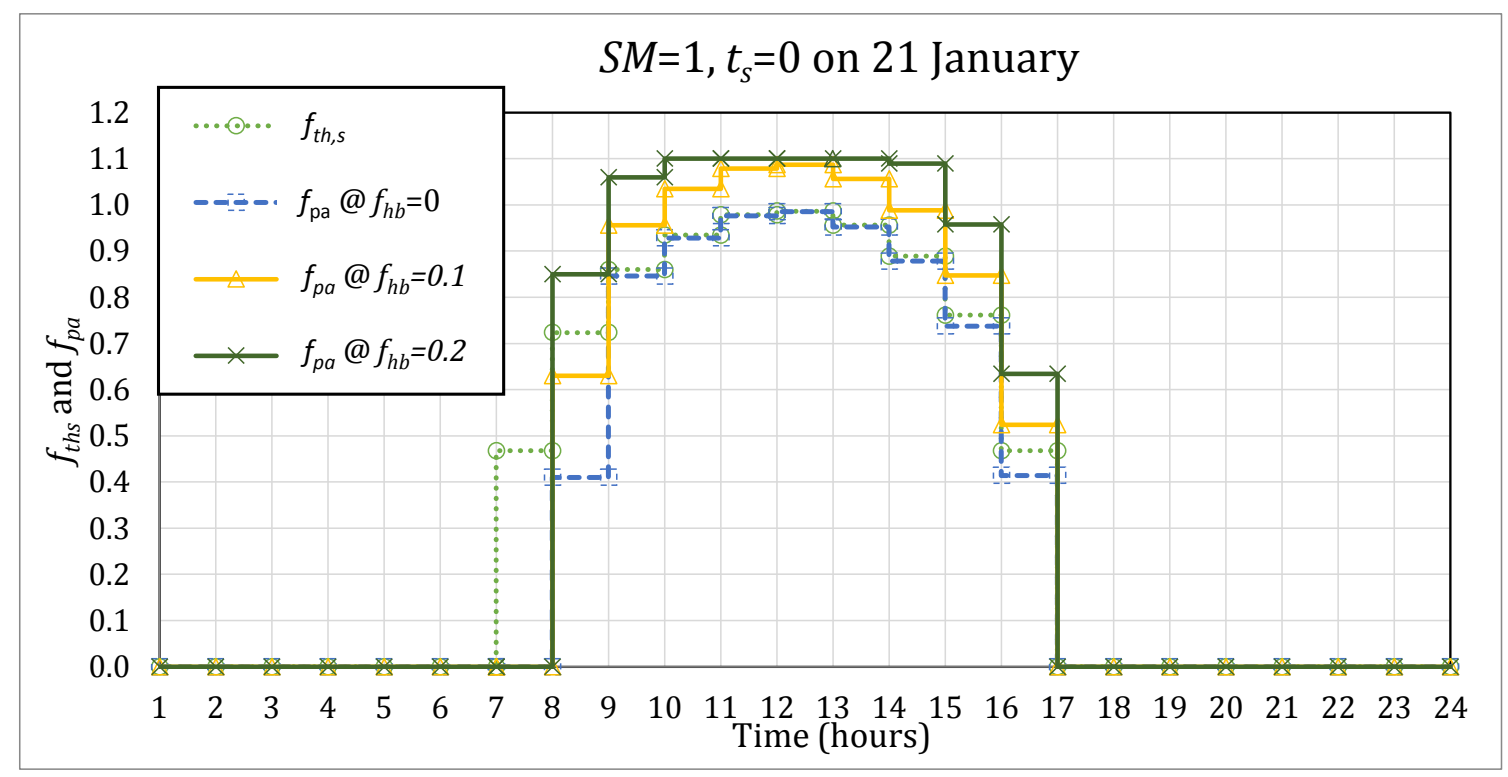

Fig. 9. Effect of Hybridisation $\left(f_{h b}=0.1\right.$ and 0.2$)$ on the Electrical Power Generated during a Typical Day for $S M=1\left(t_{s}=0\right)$

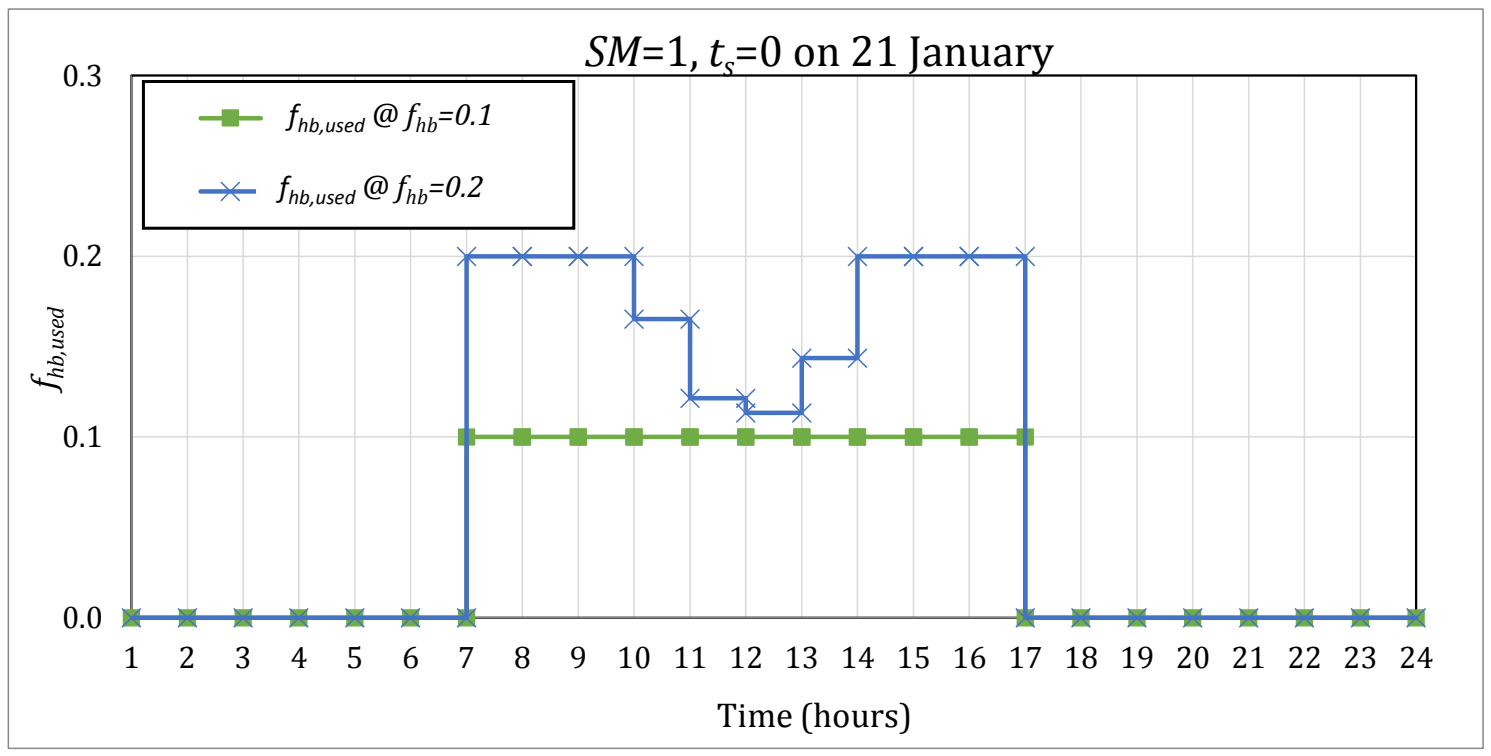

Fig. 10. Fraction of Hybridisation Used During a Typical Day for $S M=1\left(t_{s}=0\right)$ 


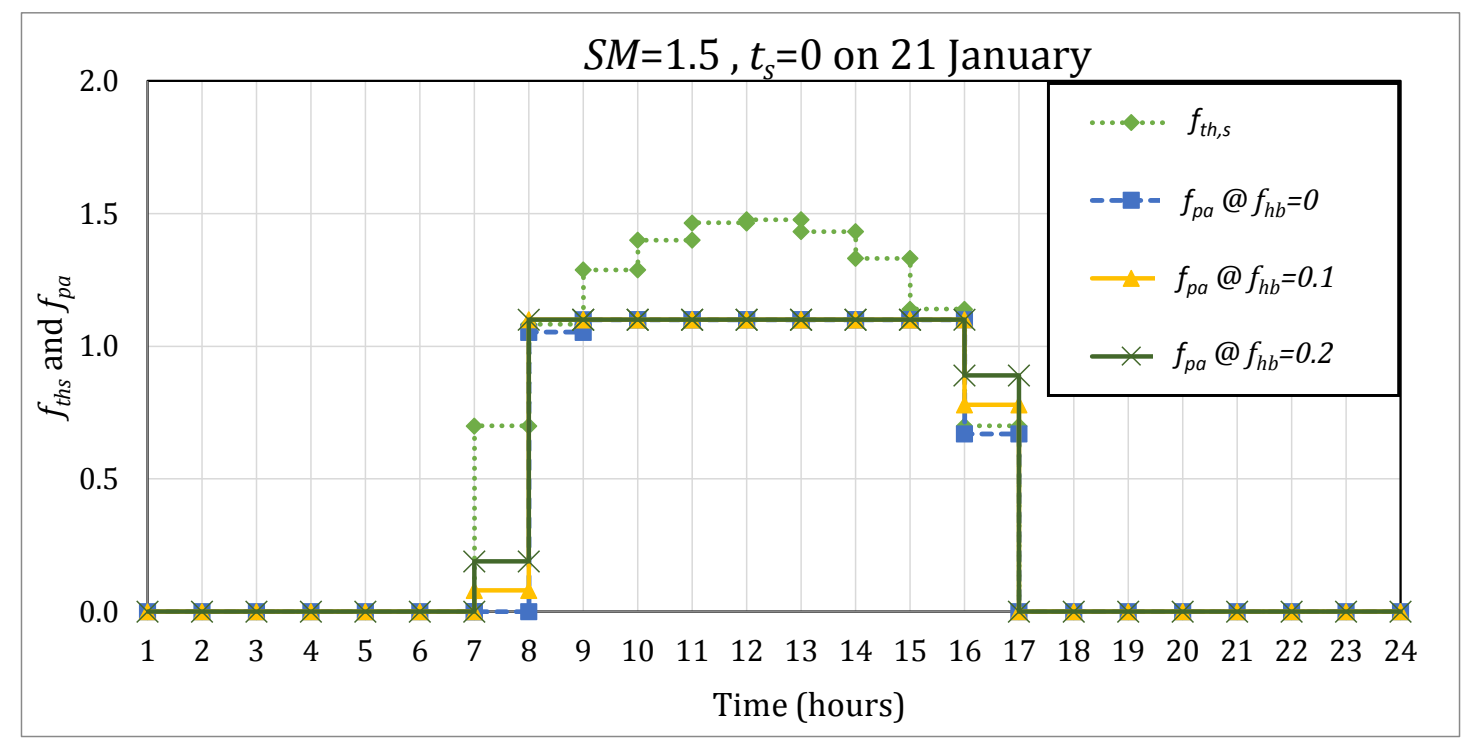

Fig. 11. Effect of Hybridisation $\left(f_{h b}=0.1\right.$ and 0.2$)$ on the Electrical Power Generated during a Typical Day for $S M=1.5\left(t_{s}=0\right)$

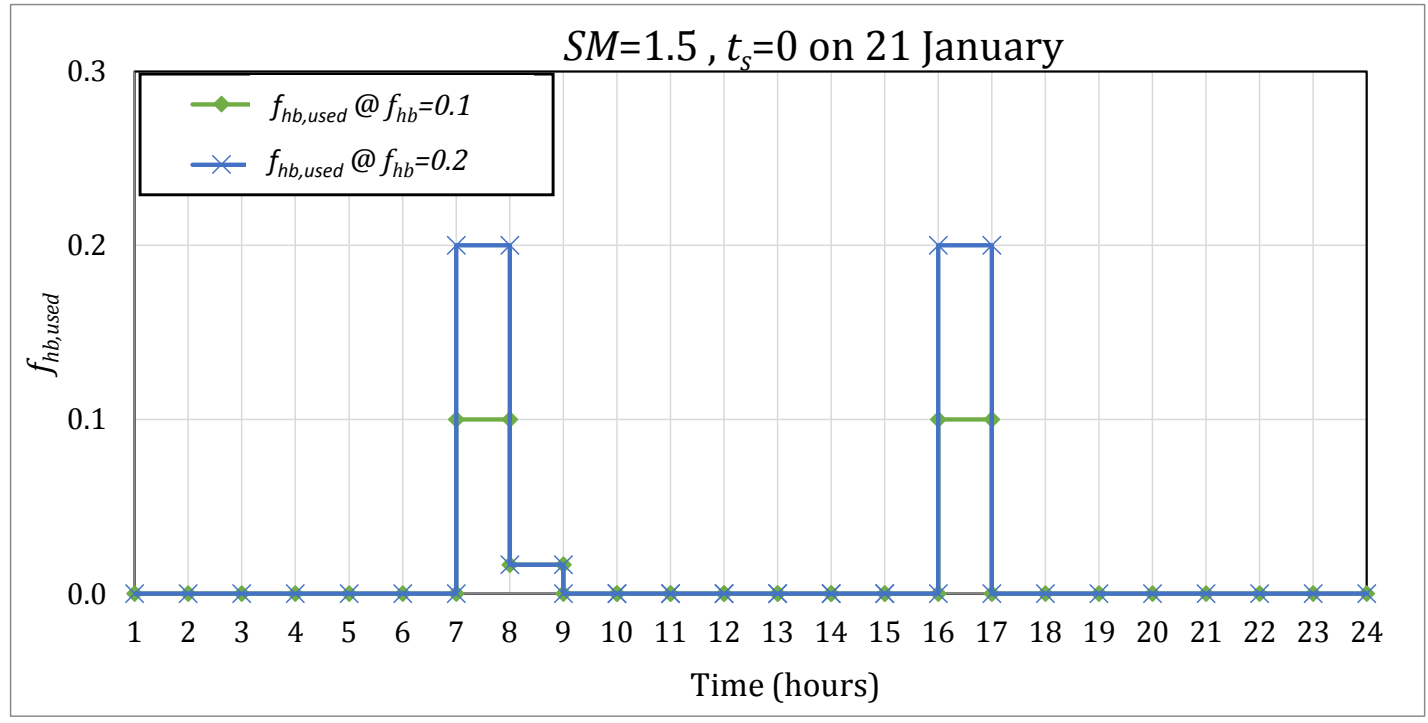

Fig. 12. Fraction of Hybridisation Used During a Typical Day for $S M=1.5\left(t_{s}=0\right)$ 


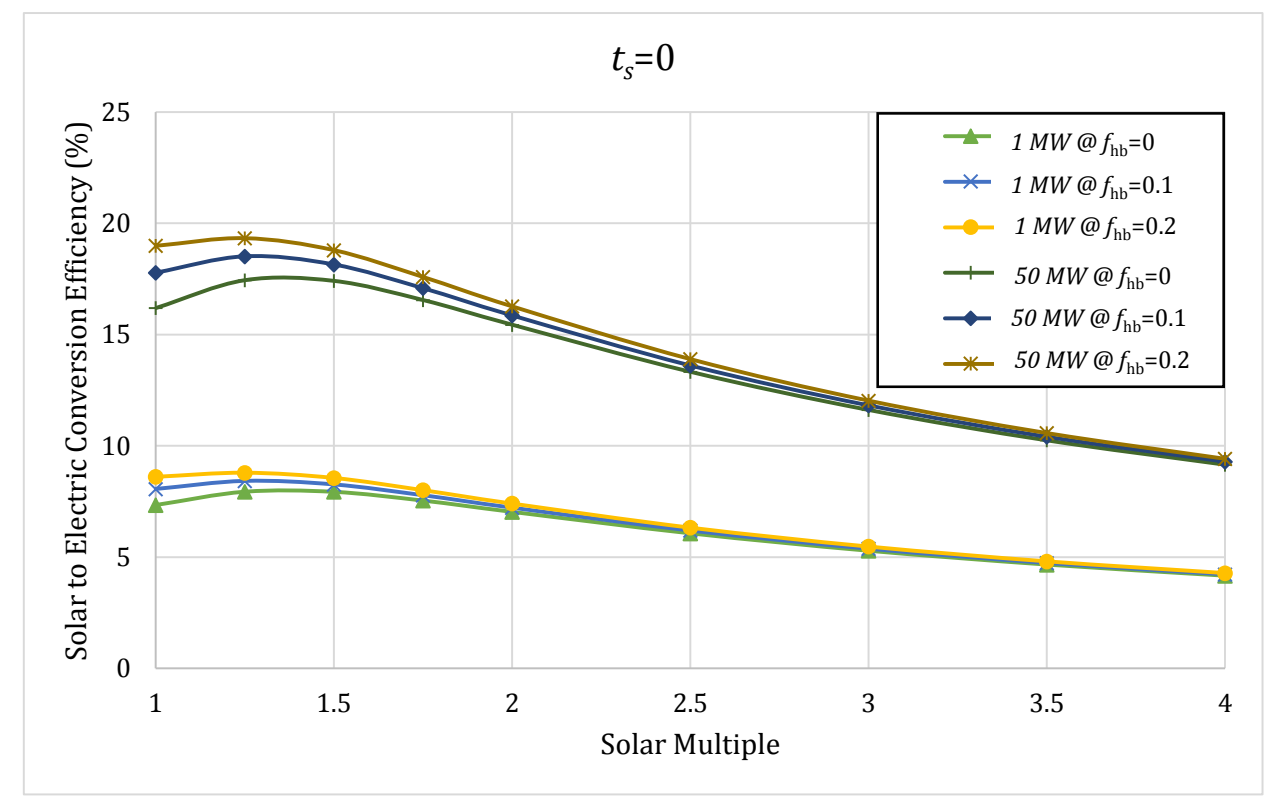

Fig. 13. Variation of $\eta_{s-e}$ with $S M$ for $f_{h b}=0,0.1$ and $0.2\left(t_{s}=0\right)$

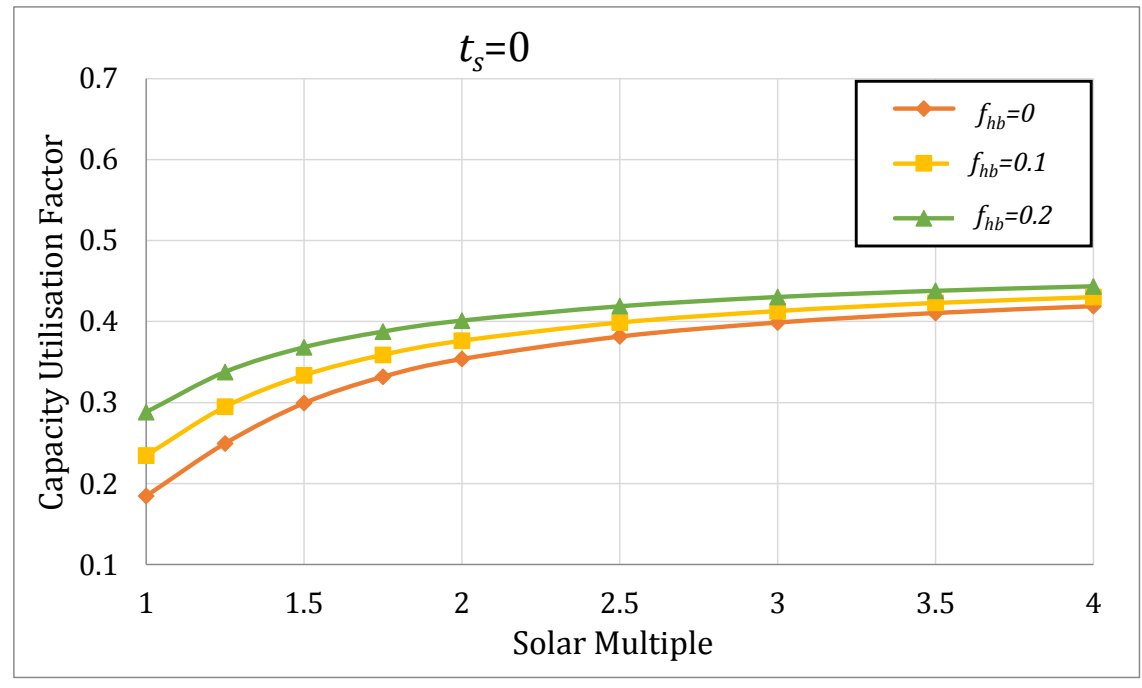

Fig. 14. Variation of CUF with $S M$ for $t_{s}=0$ hours and $f_{h b}=0,0.1$ and 0.2 


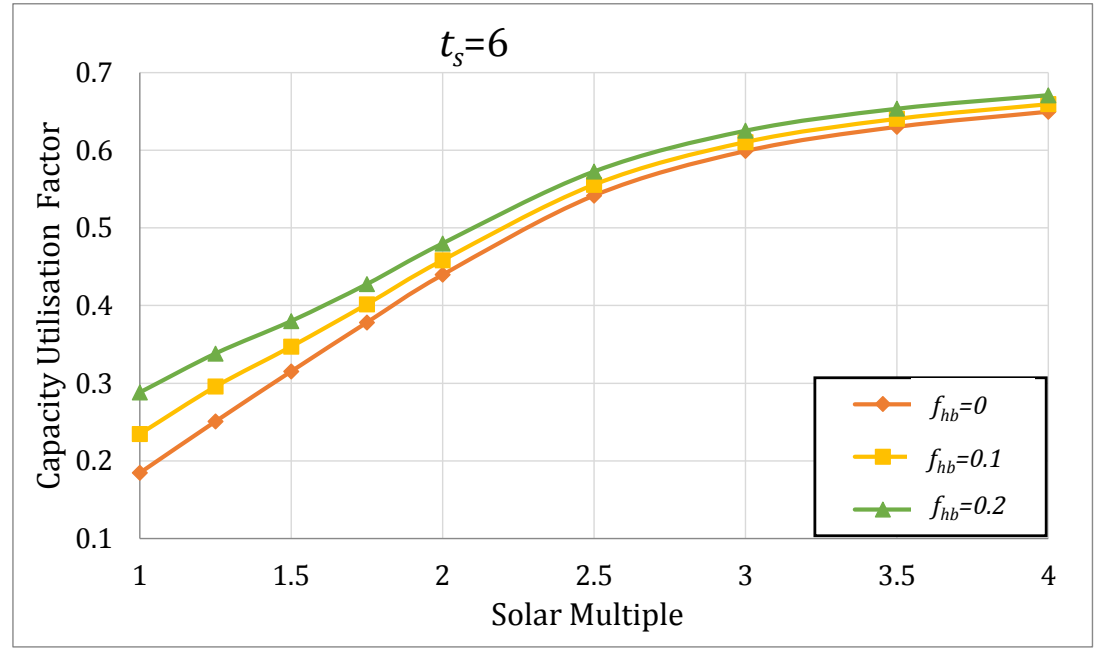

Fig. 15. Variation of CUF with $S M$ for $t_{s}=6$ hours and $f_{h b}=0,0.1$ and 0.2

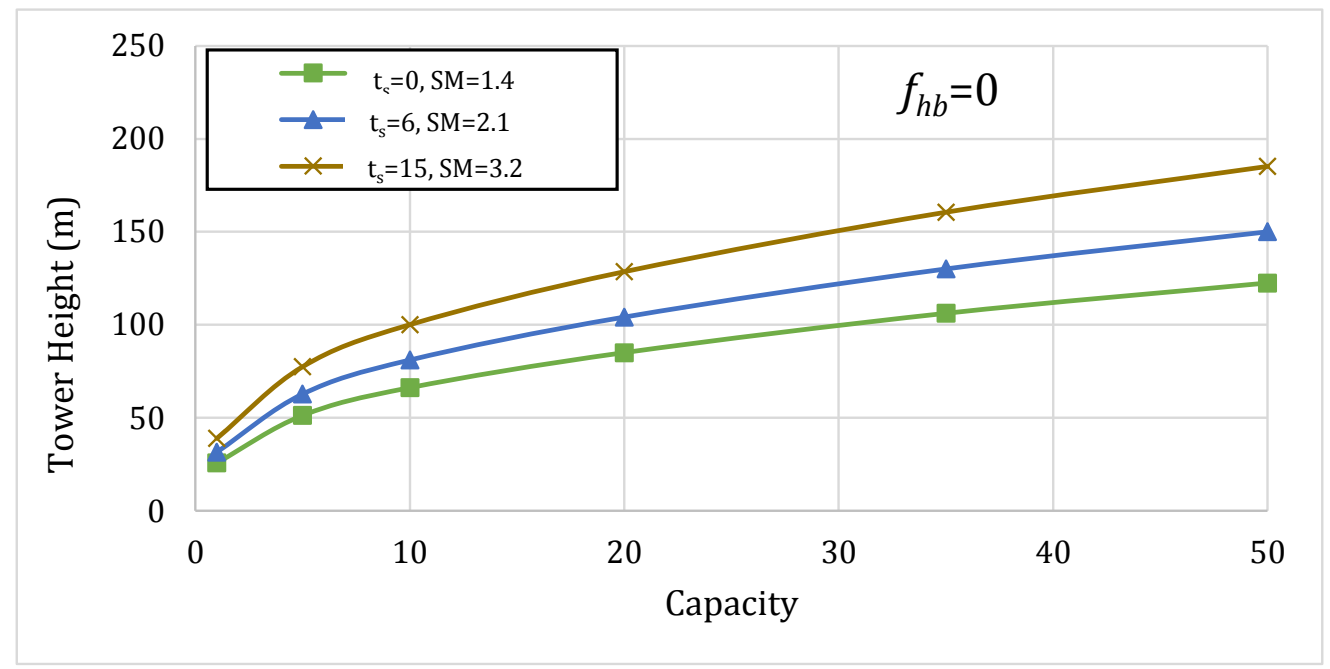

Fig. 16. Tower Height vs. Capacity for $t_{\mathrm{s}}=0,6$ and 15 at Optimum $S M\left(f_{h b}=0\right)$ 
Table 1: Input Parameters to the Model

\begin{tabular}{cc}
\hline Input Parameter & Value \\
\hline $\begin{array}{c}\text { Minimum non-dimensional distance from } \\
\text { the tower }(r / h)_{\text {field } \min }\end{array}$ & 0.5 \\
$e_{l}$ contour value $\left(\mathrm{MWh} / \mathrm{m}^{2}\right)$ & 0.16 \\
Non-dimensional length $/$ width of & 0.25 \\
elemental area, $d_{x} / h$ or $d_{y} / h$ & 0.95 \\
Heliostat (mirror) efficiency $\left(\eta_{m}\right)$ & Clear sky \\
Attenuation model considered & 0.8 \\
Receiver efficiency $\left(\eta_{\text {receiver }}\right)$ & 0.95 \\
Heat exchanger efficiency $\left(\eta_{h e}\right)$ & 0.97 \\
Thermal storage efficiency $\left(\eta_{s t}\right)$ & \\
\hline
\end{tabular}

Table 2: Output Data and Validation (Using Default $e_{l}$ Value $=0.16$ )

\begin{tabular}{|c|c|c|c|c|c|c|}
\hline \multirow[b]{2}{*}{ Parameter } & \multicolumn{3}{|c|}{ Gemasolar } & \multicolumn{3}{|c|}{ Crescent Dunes } \\
\hline & Actual & $\begin{array}{l}\text { From } \\
\text { Model }\end{array}$ & $\begin{array}{c}\text { Error } \\
(\%)\end{array}$ & Actual & $\begin{array}{l}\text { From } \\
\text { Model }\end{array}$ & $\begin{array}{c}\text { Error } \\
(\%)\end{array}$ \\
\hline Tower height (m) & 140 & 124 & $-11.8 \%$ & 195 & 213 & $14.8 \%$ \\
\hline Mirror area $\left(\mathrm{m}^{2}\right)$ & 304750 & 285737 & $-6.2 \%$ & 1197148 & 1102803 & $-8.4 \%$ \\
\hline Land area $\left(\mathrm{m}^{2}\right)$ & 1550396 & 1565123 & $0.9 \%$ & 6474970 & 7341265 & $4.4 \%$ \\
\hline $\begin{array}{l}\text { Annual electrical } \\
\text { energy generated } \\
\text { (MWh/year) }\end{array}$ & 110000 & 105487 & $-4.1 \%$ & 500000 & 542952 & $8.6 \%$ \\
\hline
\end{tabular}

Table 3: Parameters Considered for Analysis

\begin{tabular}{cc}
\hline Parameter & Value Range \\
\hline Design capacity (MW) & $1,5,10,20,35,50$ \\
Hours of thermal storage $\left(t_{s}\right)$ & $0,6,15$ \\
Fraction of hybridisation $\left(f_{h b}\right)$ & $0,0.1,0.2$ \\
\hline
\end{tabular}

Table 4: Effect of Attenuation for $S M=2.1$ (optimum) and $t_{s}=6$ hours $\left(f_{h b}=0\right)$

\begin{tabular}{ccccc}
\hline \multicolumn{2}{c}{ Clear Day } & \multicolumn{2}{c}{ Hazy Day } \\
\hline $\begin{array}{c}\text { Capacity } \\
(\mathbf{M W})\end{array}$ & $\begin{array}{c}\text { Annual Electrical Energy } \\
\text { Generated }(\mathbf{M W h})\end{array}$ & $\begin{array}{c}\boldsymbol{\eta}_{\boldsymbol{s}-\boldsymbol{e}} \\
(\boldsymbol{\%})\end{array}$ & $\begin{array}{c}\text { Annual Electrical Energy } \\
\text { Generated (MWh) }\end{array}$ & $\boldsymbol{\eta}_{\boldsymbol{s}-\boldsymbol{e}}(\boldsymbol{\%})$ \\
\hline $\mathbf{1}$ & 4059 & 8.77 & 4029 & 8.55 \\
$\mathbf{5 0}$ & 200343 & 19.11 & 193666 & 17.13 \\
\hline
\end{tabular}

